\title{
William Close (1775-1813): medicine, music, ink and engines in the Lake District
}

\author{
Damian Gardner-Thorpe MRCS MRCGP ${ }^{1}$ Christopher Gardner-Thorpe FRCP FACP 2 John Pearn FRCP FRACP 3
}

J R Soc Med 2004;97:599-602

Within the chronology of medicine there are occasional figures - for example, Leonardo da Vinci on a broader canvas - whose inventiveness has bequeathed valuable legacies in diverse fields of human endeavour. Erasmus Darwin (1731-1802) ${ }^{1}$ was one such, Ferdinand von Helmholtz (1821-1894) another. ${ }^{2}$ We believe that to this company should be added the little-known Lakeland surgeon and apothecary, William Close (1775-1813). In his brief life of 38 years, in addition to 'diligent attention to the duties of his profession' ${ }^{3}$ he contributed to the broader betterment of humankind with an extraordinary array of inventions ${ }^{4}$ - notably in mine safety, brass musical instruments and hydraulics. Two hundred years have elapsed since this kind and respected village doctor invented his 'Engine for raising water by the lateral Communication of Motion'. We believe that this is an appropriate time to record a short biography.

\section{PERSONAL AND PROFESSIONAL LIFE}

William Close was born of Yorkshire and Lake District lineage 'about the 25th of May, 1775'.4 His parents moved to the Isle of Walney, in the Lake District of north-west England, where William was educated by the Reverend Samuel Hunter, the curate-schoolmaster. In 1790, when 15 years of age, William was apprenticed to Mr Roger Parkinson, surgeon of Burton-in-Kendal, where he lived until completing his indenture in $1796 . .^{4}$ During the next year (1796-1797) he attended the University of Edinburgh Medical School and, obtaining his Diploma on 18 April 1797, immediately began medical and surgical practice at Dalton where he spent the remaining 16 years of his life.

The Furness peninsula, with the small town of Daltonin-Furness at its centre, was both rural and industrial. An extensive rural landscape was dotted with coal, copper, slate, saltpetre and iron-ore mines. The Industrial Revolution saw one of its early centres in the region, with iron worked and smelted in Furness for the emergent Barrow industries of shipbuilding and heavy industry. ${ }^{5}$

${ }^{1} 27$ Marlborough Buildings, Bath BA1 2LY; ${ }^{2}$ The Coach House, 1A College Road, Exeter EX1 1TE, UK; ${ }^{3}$ Royal Children's Hospital, Herston, Brisbane Q4029, Australia

E-mail: cgardnerthorpe@doctors.org.uk
Close involved himself in the trades of his patients, was friends with the miners, and involved himself in all aspects of countryside life. He was fond of riding_ ' an absolute necessity for a surgeon in that large and sparsely populated district'. ${ }^{4}$

In 1803 he married Isabel Charnock of the village of Newton, one mile south of Dalton. The couple had two children, John (born in 1805) and Jane (born in 1806). Close was well regarded as the surgeon and apothecary of the district. Details survive of his stocks of drugs and the books and scientific equipment and chemicals he obtained for his dispensary. He lived frugally and did not own his own house. He was described as 'a little slender man, very clever, but rather changeable ... and one who devoted himself assiduously to his professional duties, and at the same time found leisure, not only for careful investigation and research into the history, topography and archaeology of Furness, but in the arts of drawing and music . . . and to philosophical experiments [physics] and the various departments of general literature and was an expert shorthand writer' 4

In 1799, within three years of Jenner's discovery of vaccination to prevent smallpox, he introduced inoculation to the peninsula of Furness. In the days before institutional ethics committees

'he took up a temporary residence in Rampside [a village near the sea, six miles southeast of Dalton], and made a proposal to have all the children of the lower classes, thereabouts, inoculated at his expense. The vaccine disease having gone through its progress, several of the children were exposed to the infectious effluvia arising from other children in the neighbourhood, who were ill of the confluent smallpox, but all escaped without manifesting any symptoms of infection. This experiment, made so openly, removed any doubt and prejudice, and confirmed the efficacy of the new discovery in the most satisfactory manner, and during the next five years the neighbourhood was free from the smallpox'.4

After his death, a single one-paragraph obituary described William Close as a doctor 'deservedly esteemed for his candour, sincerity and benevolence ....3 The 
miners in his community doubtless esteemed him most for his contributions to work safety. He invented an improved lamp for burning tallow ${ }^{6}$ and a new method for sandtamping of explosive charges ${ }^{7}$ and he also published, with full acknowledgement to the primary inventor, a colleague's technique for preventing premature explosion of such charges. ${ }^{8,9}$ However, in this article we focus on his contributions in other spheres.

\section{MUSIC}

William Close was a good musician and his particular interest in brass instruments led him in 1797 to establish a workshop in his home and apothecary shop in Dalton. He made brass and, occasionally, silver trumpets, French horns and bugles. Brass instruments at that time were essentially restricted to notes of the harmonic progression. For example, a trumpet with a tube length such that the fundamental note was D could obtain D-D-A-D-F\#-A-C-D and so on by varying the embouchure. (Expert players were able to achieve additional notes by a technique known as lipping.) Since 1715, crook, or shanks had been inserted into instruments to alter the fundamental note. In his workshop, Close built and experimented with modifications to these crooks. His first invention was a drainage spittlecock. A patent application on 2 September 1811 described these cocks as 'Tubes to let off the accumulated moisture arising from condensation during performance'. The patent was granted the following year. It was perhaps as a consequence of making these drainage holes that Close hit upon the idea of making further holes that would allow the performer to play an octave scale. ${ }^{10}$ As early as 1798 he had purchased an organ pipe and box and quantities of rolled lead and pewter. Prototype uncoiled trumpets were crafted out of brown soap and paper, and in these models he found where to place holes that would widen the instrument's capabilities. From 1801 to 1812 he made and sold trumpets, bugles and French horns with these modifications. They were known as 'Polyphonian' instruments and he sent specimens to the bandmaster of the Headquarters of the British Army in Spain, to the Masters of the Duke of Kent's and the Duke of Cumberland's bands, and also to Thomas Percival, Musical Instrument Maker of 89 St James Street, London. ${ }^{4}$

In 1810 Close gave a paper to the Society of Arts and Manufacturers under the title Improvements in Various Brass Instruments. The Society subsequently offered him its Silver Medal $^{3}$ but he declined it.

Two years later he was successful in obtaining a patent for his keyed brass instruments which 'by means of certain tubular branches, additaments, or appendages, communicating with the main channels of the said instruments, having in them holes or ventiges upon which, by operation of fingering, the said additional tones or notes are respectively produced. The trumpets thus constructed are, by reason of their multifarious sounds, styled "polyphonian trumpets" '.11

Close's inventions have not been sufficiently acknowledged in the history of music. Apart from the successful patents, his only advertisement was the word Polyphonian on the shop door of Thomas Percival, his supporter and instrument-maker in London (to whom the dying Close sold his patents). On 19 August 1812 Percival wrote to Close in Dalton that 'numbers of people enquire the meaning of POLYPHONIAN upon my DOOR PLATE, it is cut in Old English, and what from the word itself and the manner of Engraving, many spell a long time at it'. ${ }^{4}$

The era of Polyphonian instruments lasted only some eight years. In 1818 valves were invented in Germany, ${ }^{12}$ replacing the keyed finger holes. However, Close deserves credit for his contribution to the brass instruments of today which allow the musician to play a homogeneous chromatic scale of four octaves.

\section{INDELIBLE INK}

William Close experimented with various substances to make indelible inks, both black and red. Because the inks available in his day did not produce a permanent written text the 'testimony of writing', as he described it, could be lost, erased or defaced by exposure to humidity, or fading, or particularly by the deliberate use of 'oxigenated muriatic acids' [hypochlorite bleach]. He wrote that, since the invention of printing, there was less need for indelible ink but that, particularly in the case of individual texts and legal documents, permanent ink was needed to preserve 'the transactions of the day, and to ratify the affairs of the future'. ${ }^{13}$

The ink of his time was made by the addition of ferrous sulphate and gum or sugar to an infusion of oak galls. After experimenting with various substances he devised the following recipe for indelible black ink:

'Take of oil of lavender, 200 grs. copal in power, 25 grs, lamp black from $2 \frac{1}{2}$ to 3 grs with the assistance of a gentle heat, dissolve the copal in the oil of lavender in a small glass phial, and then mix the lamp black with the solution upon a marble slab ... put the composition into a bottle, and keep it excluded from the air'. ${ }^{13}$

His indelible red ink was coloured with 'red sulphuret of mercury'. Copal is the dried and crystalline resin from any one of four or five genera of South American tree, including Bursera copal. A letter in reply to Close's article questioned the indelibility if the writing 'was washed with camphorated 
spirits ${ }^{14}$ but there exists no report of any such experiment being made either by Close or by others.

\section{HISTORIAN}

In addition to his inventive pursuits Close evinced a passion to record, describe and interpret local features of prehistoric, archaeological and contemporary significance. At age 30 he published a new edition of West's Antiquities of Furness, ${ }^{3,4}$ and his personal research in the local History, Topography and Archaeology of Furness ${ }^{4}$ extended over the first eight years of his life in Dalton. An 86-page supplement to Antiquities of Furness contains articles on local archaeology, botany and geology, accounts of the architecture of Walton Castle and Furness Abbey, descriptions of the wells of Northscale Walney and explanations for their 'alternating water springs' and an account of the prehistoric Ella Barrow at Pennington. He wrote about the ancient church bells and stained glass in Dalton Church, about local villages and their people, about buildings including those of Gleaston, Coniston, Pennington and the two Urswick villages, and about farming practices and unique local farmers' tools including the 'Furness sickle' and the 'Furness indented swingle tree'; ${ }^{4}$ a swingle-tree is the crosspiece of a carriage or plough to which the traces of harnessed horses are fixed. Close also analysed 250 years of births, deaths and marriages recorded in the Dalton Parish Church registers, with special attention to the plague in Dalton from 1631 to 1632 during which $545^{4}$ of the 2000 in the parish died. ${ }^{15}$ As lately as 1772 smallpox (which Close had eliminated from the region in 1799) had killed as many as 41 residents.

During the last 10 years of his life, Close prepared a manuscript entitled Itinerary of Furness and the Environs which, had not the author died so young, would have been as widely known as West's Guide to the Lakes. The manuscript provides brief information about all the towns and villages within 21 miles of Ulverston, 'containing the distances ... with notices of County Seats, picturesque scenery and all objects meriting attention .... and much information dealing with the manners and customs of the inhabitants; with copies of title deeds and letters of historical significance'. ${ }^{4}$ This work, together with his interest in indelible inks, reflects Close's perceived responsibility to record for posterity that which otherwise would be lost forever.

\section{HYDRAULIC ENGINEERING}

Close saw pragmatic engineering challenges in the industrial and municipal world in which he lived. Aged 29, in 1804 he addressed the engineering problem of air leaking into industrial condensers and into water-holding reservoirs and siphons. He solved it by means of a double-encasing water- filled container-jacket that 'unless the workmanship be very bad' gives an airtight seal. ${ }^{16}$

Walney Island where he had grown up, and the Furness peninsula of which it is a part, is a water-oriented society. The new doctor became interested in hydraulic engineering and what today would be called fluid mechanics. In his paper Observations on the practicability and expense of recovering land from the sea at Walney Channel he proposed damming Walney Channel, for the funding of which he presented a detailed business plan 'with a clear gain of $£ 72,000$ '. ${ }^{4}$ The local landowners did not support the proposal.

Dalton is situated upon a dry eminence of limestone, and water springs in the neighbourhood were not easily accessed: 'the inhabitants experience considerable fatigue and inconvenience in providing the quantity of water which is indispensably necessary for culinary and domestic purposes'. Close responded to this challenge by inventing several pumping devices, the details of which he published between 1801 and 1805. ${ }^{17-22}$ His first hydraulic engine was a modification of an earlier device designed by Goodwin. ${ }^{23}$ His final engine, working on a siphon principle and with a complex system of leather valves, used air entrained from water moving in this siphon (Figure 1). He built a working prototype in Dalton, and raised water ' 12 feet above the cistern at the rate of $20 \frac{1}{2}$ pints per hour'.

\section{CONCLUSION}

In 1811, aged 36 years, Close started coughing blood. Tuberculosis was diagnosed and he died two years later at the height of his inventive powers. He was buried, at his own request, at Walney in a spot of ground upon which he

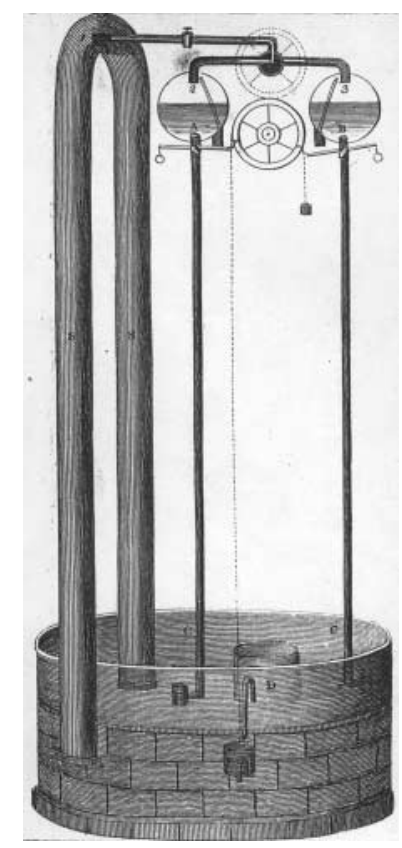

Figure 1 Hydraulic apparatus to raise water above its level (from Nicholson's J 1802;1:27-32) 
had often played when a boy, ${ }^{3,4}$ in a grave which he specified should be nine-feet deep and without a headstone. After his death his widow allowed many of his papers to be dispersed or destroyed. ${ }^{4}$

It is surprising that William Close and his inventions have been so little acknowledged. One reason perhaps was the remoteness of the region in which he lived. His biographer, Harper Gaythorpe, opined that the absence of any national acknowledgement of Close's work 'may have arisen from the fact that even today [1903] the geographical position of the Furness district seems to be still imperfectly known'. ${ }^{4}$ Another possible reason for neglect was that his polymath interests did not allow him to be 'compartmentalized' or stereotyped in either popular or professional terms. He was said to have attempted too much, and 'had he devoted more time to perfecting some one branch of work, his fame would have been more widely known' ${ }^{4} \mathrm{He}$ was a humble yet extraordinary man.

Acknowledgments We thank Mrs Lynne Packer of the University of Queensland for much help.

\section{REFERENCES}

1 King-Hele D. The Essential Writings of Erasmus Darwin. London: MacGibbon \& Kee, 1968

2 Pearn JH. Professor Herman Ludwig Ferdinand von Helmholtz 1821 1894. In: A Doctor in the Garden. Brisbane: Amphion Press, 2002:184-5

3 Anonymous. Obituary: with Anecdotes of Remarkable Persons. $\mathrm{Mr}$ Wm. Close, surgeon and apothecary. Gentleman's Magazine 1813;83:298

4 Gaythorpe H. William Close: surgeon, apothecary, historian, musician of Dalton-in-Furness. Barrow Naturalists' Field Club Annual Rep 1909; 17:1-15

5 Buchanan RA. Industrial Archaeology in Britain. London: Book Club Associates 1971

6 Close W. On the Lamp for Tallow, and the Combustion of that Material. Nicholson's J 1799;3:547-8

7 Close W. [On Improved Methods for Blasting Rocks]. West's Antiquities of Furness. Furness: G. Ashburner, 1804:393
8 Close W. Observations on blasting Rocks; with an Account of an Improvement, whereby the Danger of accidental Explosion is in a great Measure obviated. Nicholson's J 1805;12:171-4

9 Close W. Account of the Art and Instrument used for boring and blasting Rocks; with Improvements. Nicholson's J 1806;13:192-6

10 Close W. Observations on the Defects of the Trumpet, Bugle and French Horn, and the Extensions of their Musical Powers. Furness, 1812

11 UK Patent Office. Rolls Chapel Reports. 8th Report. Abridgement of the Specification of Patent No. 3505. [William Close of Dalton] for 'Improvements on trumpets of different denominations, namely, the treble or common trumpet the French horn or tenor trumpet, and the bugle horn: p. 92

12 Baines A. The later brass. In: Musical Instruments Through the Ages. London: Penguin Books, 1969: 306-8

13 Close W. Composition of Writing Ink, possessing the permanent Colour, and other essential Properties, of the Ink used for Printing. Nicholson's J 1802;11:145-50

14 Sheldrake T. On the preparation of indelible ink. Nicholson's $J$ 1802;11:237-8

15 The Gaythorpe Collection in Barrow Library, Barrow-in-Furness [www.dalton-in-furness.org.uk/dalton-online/history]

16 Close W. On the Combinations for supplying Worm Tubs with Cold Water, by the Syphon, with an easy Method of securing the Joints of such Hydraulic Apparatus against the Admission of the External Air. Nicholson's J 1801;7:191-2

17 Close W. Description of an Engine for raising water by the lateral motion of a stream of water through a conical tube. Nicholson's $J$ $1801 ; 4: 293-8 ; 493-5$

18 Close W. New application of the Syphon to raise water above the surface of the reservoir. Nicholson's $J$ 1801;4:547-50; 1802;5:22-3

19 Close W. Construction of an hydraulic apparatus, which by means of the Syphon raises water above its level, and performs its alterations without attendance. Nicholson's J 1802;1:27-32

20 Close W. Concerning the Engine for raising Water by the lateral Communication of Motion. Nicholson's J 1801;4:493-5

21 Close W. Construction of an Hydraulic Apparatus, which by means of the Syphon raises Water above its Level, and performs its alterations without attendance. Nicholson's J 1802;1:27-32

22 Close W. Description and effects of an Apparatus for raising Water by means of air condensed in its descent through an inverted Syphon. Nicholson's J 1805;12:16-28

23 Boswell JW. Improvements in the Hydraulic Engine of Schemnitz, and that of Mr. Goodwyn; with comparative Remarks on the most useful Applications of each, and some Facts relative to the Invention of the pressure Engine. Nicholson's J 1802;2:2-6 